\title{
Constitutional differences between men recruited for driving and non-driving occupations
}

\author{
R. M. OLIVER \\ Civil Service Medical Department, Whitehall, London, S.W.1.
}

\begin{abstract}
Oliver, R. M. (1969). Brit. J. industr. Med., 26, 289-293. Constitutional differences between men recruited for driving and non-driving occupations. Earlier studies of busmen have shown that driver recruits differ physically from conductor recruits and these differences are probably constitutional in origin. This was important in relation to the differing ischaemic heart disease experience of drivers and conductors.

The present study attempts to confirm that those recruited for driving as opposed to comparable non-driving jobs in the Post Office differ from each other physically in a similar way to the busmen recruits.

By a study of old records of certain measurements made on Post Office recruits in two age groups (21-26 years and 40-45 years) it was shown that mail van drivers were on average nearly $0.5 \mathrm{in} .(1.27 \mathrm{~cm}$.) taller than postal delivery workers. The difference was less in the older age group. In both age groups the mail drivers were heavier (approx. 5 and $7 \mathrm{lb}$. (2.3 and $3.2 \mathrm{~kg}$.) respectively) and slightly bigger round the chest than the delivery postmen. Some of the additional weight of drivers can be explained by their greater mean height, but all of it cannot be so explained. For any given height, mail drivers tended to be heavier than delivery postmen.

This study supports the view that men who choose mainly sedentary driving jobs are constitutionally different from those who choose more active but otherwise comparable nondriving jobs. It is suggested that this may be an important consideration in any investigations into the morbidity affecting men in driving and possibly other physically inactive jobs.
\end{abstract}

It has been shown that the physique of London bus drivers is different from that of conductors (Morris, Heady, Raffle, Roberts, and Parks, 1953; Morris, Heady, and Raffle, 1956; Heady, Morris, Kagan, and Raffle, 1961; Oliver, 1964; 1967). Drivers are on average taller, heavier, broader round the chest and waists, and more obese than conductors. Part of this difference in physique can be explained by the different exertional requirements of these two jobs. It has, however, been shown (Oliver, 1964; 1967) that some of these physical differences are present in young men before they are recruited for employment as drivers or conductors. This led to the suggestion that, although subsequent occupation almost cer- tainly influenced the physique of busmen, the fundamental cause of the known later differences in physique between drivers and conductors might be an inherited factor. This is clearly important when the causes of the known differences in ischaemic heart disease experience of bus drivers and conductors are being considered (Morris et al., 1953; Morris and Raffle, 1954; Heady et al., 1961). If one inherited factor, namely physique, is carried by a man into his occupation, it is reasonable to suppose that other inherited factors, such as a susceptibility to ischaemic heart disease, may also be carried.

In my earlier studies of busmen I discussed the reasons why the physical characteristics of a young 
man lead him into driving as opposed to a comparable non-driving job. Differences in height between bus drivers and conductors were probably, at least in part, explained by selection by the employer. Other differences in physique could not be accounted for in this way. Self selection seemed to play an important role in many instances. Whatever the reason for the physical differences in busmen, there is strong evidence in support of an hypothesis that men who take up driving are constitutionally different from those who prefer conducting. This has important implications so far as the ischaemic heart disease experience of bus drivers and conductors is concerned.

It was therefore thought useful to test the hypothesis further to see whether similar constitutional differences existed in men employed in other comparable driving and non-driving jobs. An opportunity to do this arose in the Post Office where some young men were recruited for predominantly driving duties (motor mail drivers) and some for predominantly postal delivery work (postmen). The purpose of this paper is to report and comment on the significance of some of the physical characteristics of these two groups of employees.

\section{Method}

All new motor mail drivers and postmen who passed their initial interview were medically examined before employment. Although the full results of this physical examination were not easily traceable every candidate examined at the General Post Office Headquarters Medical Centre in the City of London has had his name recorded in a ledger. As well as the candidate's name, age, and grade there is also noted the height, weight, and chest measurements. These records formed a simple, albeit crude, way of obtaining information about the average physique of motor mail drivers and postmen. Men in two age groups were considered. The first were aged 21-26 years inclusive at the time of the examination; and the second were aged 40-45 years inclusive at the time of the examination. These six-year age groups were chosen so as to include sufficient numbers of men, particularly motor mail drivers, who had been recruited during a reasonably short span of months. No sampling procedure was employed. All men recruited in the groups under consideration were included in the results.

The recruitment period arbitrarily chosen for this study was March 1951 to March 1952. For the group of motor mail drivers, it became apparent that too few had been recruited during this period for useful statistical analysis, and the recruitment period was therefore extended to include all men recruited from July 1950 to October 1952. Thus, the recruitment periods during which the motor mail drivers and postmen were compared were not identical, although it is unlikely that this is important.

Motor mail drivers were not recruited below the age of 21 years so that this was the youngest age at which it was possible to compare them with postmen. This governed the choice of 21 years as the youngest age group considered.

In the age group 21-26 years, data were collected on 133 motor mail drivers and 762 postmen. In the age group 40-45 years, data were collected on 96 motor mail drivers and 369 postmen.

The following data were compared:-

\section{Height}

This was measured to the nearest 0.25 in. $(0.63 \mathrm{~cm}$.) with the subject standing erect against a rule. The height was measured with the subject wearing shoes and 1 in. $(2.54 \mathrm{~cm}$.) was deducted to give the estimated actual height which was then recorded.

\section{Weight}

This was measured using a balance scale to the nearest $0.5 \mathrm{lb}$. $(0.22 \mathrm{~kg}$.) with the subject wearing normal indoor clothes and shoes. A deduction of $4 \mathrm{lb}$. $(1 \cdot 8 \mathrm{~kg}$.) was made and this estimated stripped weight was recorded.

\section{Chest circumference}

This was measured at rest to the nearest $0.5 \mathrm{in} .(1.27 \mathrm{~cm}$.) at approximately nipple level beneath the jacket or waistcoat (that is the 'tailor's chest' measurement). Not all the chest circumference data were used in the calculations since it was apparent from the preliminary analysis of the results from those men recruited between March 1951 and March 1952 that this physical characteristic would not be of great significance. The calculations of mean chest measurements were therefore based on 762 postmen and 85 motor mail drivers in the 21-26 year age group and 369 postmen and 59 motor mail drivers in the $40-45$ year age group.

All the above measurements were made by a nurse or other lay staff. Clearly, the method of measurement employed was not as accurate as normally desirable for a scientific study but nonetheless the method was consistent and with sufficient numbers was satisfactory for comparison between groups.

\section{Results}

Since within the period considered no sampling was involved, any observed differences between motor mail drivers and postmen must, apart from minor measurement errors, be taken as a matter of fact and not one subject to sampling error. Nevertheless, it may be argued that the differences could have arisen by chance given a much larger homogeneous physical group, the members of which independently elected to (1) apply to be motor mail drivers, or (2) apply to be postmen, or (3) do neither.

In the results that follow, the values of $P$ shown are the probabilities in favour of such a hypothesis. Where the probability is as much as 1 chance in 10 $(P=0 \cdot 1)$ no value is shown. Where the probabilities are small they suggest that motor mail drivers and postmen recruits are much more likely to have been drawn from different physical groups.

In the 21-26 year age group the motor mail drivers were on average $0.46 \mathrm{in}$. $(1 \cdot 17 \mathrm{~cm}$.) taller and $5.33 \mathrm{lb}$. 
$(2.42 \mathrm{~kg}$.) heavier than postmen (Table 1). These differences are statistically significant $(P=0.03$ and 0.001 respectively). The motor mail drivers in the 21-26 year age group were on average also $0 \cdot 22$ in. $(0.56 \mathrm{~cm}$.) bigger round the chest than postmen, but this difference is not statistically significant.

In the 40-45 year age group motor mail drivers were on average 0.37 in. $(0.94 \mathrm{~cm}$.) taller, $7.07 \mathrm{lb}$. $(3.21 \mathrm{~kg}$.) heavier and 0.4 in. $(1.02 \mathrm{~cm}$.) bigger round the chest than postmen. Only the difference in weight is statistically significant $(P=0.004)$.

It is apparent that in both age groups it was, on average, the taller and heavier man who was recruited to the grade of motor mail driver as opposed to that of postman. It is possible that the increased weight of the driver group was simply a reflection of their greater mean height and did not represent any other characteristic of physique such as obesity. This point was therefore examined further.

In Table 2 are set out the mean weights of motor mail drivers and postmen within each one-inch $(2.54 \mathrm{~cm}$.) height step.

There are wide variations in the differences in weight shown in Table 2 . This is probably due to the small numbers included in some of the height groups. Nevertheless, in the majority of height steps, particularly in those containing reasonable numbers in the middle of the height scatter, the motor mail drivers were heavier than postmen of the same height.

The Table suggests that the linear regression of weight on height should be calculated. This was done and it was found that the gain in weight per inch of additional height was $3.79 \mathrm{lb}$. for the 21-26 age group and $4.26 \mathrm{lb}$. for the $40-45$ age group, with no significant difference between motor mail drivers and postmen. If from the observed mean additional weight of motor mail drivers is deducted the amount expected because of their additional height, the following calculation can be made:-

TABLE 1

Mean Height, Weight and Chest Circumferences of Motor Mail Drivers and Postmen

\begin{tabular}{|c|c|c|c|c|c|}
\hline $\begin{array}{c}\text { Age } \\
\text { (yrs.) }\end{array}$ & & $\begin{array}{c}\text { Motor mail } \\
\text { drivers }(M M D)\end{array}$ & $\begin{array}{c}\text { Postmen } \\
(P M N)\end{array}$ & $\begin{array}{c}\text { Difference } \\
(M M D-P M N)\end{array}$ & $P$ \\
\hline $\begin{array}{l}21-26 \\
40-45 \\
21-26 \\
40-45 \\
21-26 \\
40-45\end{array}$ & $\begin{array}{l}\text { Height (in.) } \\
\text { Weight (lb.) } \\
\text { Chest circumference (in.) }\end{array}$ & $\begin{array}{r}68 \cdot 53 \\
67 \cdot 66 \\
152 \cdot 01 \\
156 \cdot 97 \\
33 \cdot 05 \\
34 \cdot 18\end{array}$ & $\begin{array}{r}68 \cdot 07 \\
67 \cdot 29 \\
146 \cdot 68 \\
149 \cdot 90 \\
32 \cdot 83 \\
33 \cdot 78\end{array}$ & $\begin{array}{l}0 \cdot 46 \\
0 \cdot 37 \\
5 \cdot 33 \\
7 \cdot 07 \\
0 \cdot 22 \\
0 \cdot 40\end{array}$ & $\begin{array}{l}0.034 \\
- \\
0.001 \\
0.004 \\
- \\
-\end{array}$ \\
\hline
\end{tabular}

TABLE 2

Mean Weights of Motor Mail Drivers and Postmen in One-inch Height Steps

\begin{tabular}{|c|c|c|c|c|c|c|c|c|c|c|}
\hline \multirow{3}{*}{$\begin{array}{l}\text { Height } \\
\text { (in.) }\end{array}$} & \multicolumn{5}{|c|}{ Age group 21-26 yrs. } & \multicolumn{5}{|c|}{ Age group 40-45 yrs. } \\
\hline & \multicolumn{2}{|c|}{$\begin{array}{c}\text { Motor mail } \\
\text { drivers } \\
(M M D)\end{array}$} & \multicolumn{2}{|c|}{$\begin{array}{c}\text { Postmen } \\
(P M N)\end{array}$} & \multirow{2}{*}{$\begin{array}{c}\text { Difference } \\
(M M D-P M N) \\
(l b .)\end{array}$} & \multicolumn{2}{|c|}{$\begin{array}{c}\text { Motor mail } \\
\text { drivers } \\
(M M D)\end{array}$} & \multicolumn{2}{|c|}{$\begin{array}{l}\text { Postmen } \\
(P M N)\end{array}$} & \multirow{2}{*}{$\begin{array}{c}\text { Difference } \\
(M M D-P M N) \\
(\text { lb. })\end{array}$} \\
\hline & $\begin{array}{l}\text { Mean wt. } \\
\quad(\text { lb. })\end{array}$ & $\begin{array}{l}\text { No. in } \\
\text { group }\end{array}$ & $\begin{array}{l}\text { Mean wt. } \\
\quad(l b .)\end{array}$ & $\begin{array}{l}\text { No. in } \\
\text { group }\end{array}$ & & $\begin{array}{l}\text { Mean wt. } \\
\quad(l b .)\end{array}$ & $\begin{array}{l}\text { No. in } \\
\text { group }\end{array}$ & $\begin{array}{l}\text { Mean wt. } \\
\quad(l b .)\end{array}$ & $\begin{array}{l}\text { No. in } \\
\text { group }\end{array}$ & \\
\hline $\begin{array}{l}62 \\
63 \\
64 \\
65 \\
66 \\
67 \\
68 \\
69 \\
70 \\
71 \\
72 \\
73 \\
74 \\
75 \\
76\end{array}$ & $\begin{array}{l}126 \cdot 0 \\
126 \cdot 5 \\
137 \cdot 5 \\
150 \cdot 2 \\
145 \cdot 4 \\
147 \cdot 0 \\
153.9 \\
156.8 \\
161 \cdot 9 \\
169 \cdot 7 \\
168 \cdot 0 \\
167 \cdot 5 \\
179.0\end{array}$ & $\begin{array}{r}1 \\
2 \\
6 \\
17 \\
20 \\
27 \\
19 \\
17 \\
12 \\
6 \\
1 \\
2 \\
2\end{array}$ & $\begin{array}{l}144.0 \\
126.7 \\
129.8 \\
135.6 \\
143.3 \\
141.7 \\
148.8 \\
149.5 \\
153.9 \\
157.6 \\
165.6 \\
169.0 \\
161.8 \\
183.5 \\
220.0\end{array}$ & $\begin{array}{r}5 \\
7 \\
30 \\
67 \\
89 \\
134 \\
128 \\
105 \\
81 \\
43 \\
35 \\
10 \\
6 \\
1 \\
1\end{array}$ & $\begin{array}{l}-0.7 \\
-3.3 \\
+0.9 \\
+6.9 \\
+3.7 \\
-1.8 \\
+4.4 \\
+2.9 \\
+4.3 \\
+4.1 \\
-1.0 \\
+5.7 \\
-4.5\end{array}$ & $\begin{array}{l}147 \cdot 0 \\
137.0 \\
144 \cdot 5 \\
132 \cdot 5 \\
140 \cdot 1 \\
155 \cdot 3 \\
160 \cdot 3 \\
159 \cdot 6 \\
170 \cdot 4 \\
171 \cdot 0 \\
180 \cdot 5 \\
190 \cdot 5 \\
196.0\end{array}$ & $\begin{array}{r}2 \\
1 \\
10 \\
4 \\
11 \\
10 \\
14 \\
10 \\
12 \\
5 \\
4 \\
2 \\
1\end{array}$ & $\begin{array}{l}141 \cdot 2 \\
136 \cdot 4 \\
138 \cdot 8 \\
145 \cdot 6 \\
144 \cdot 2 \\
143 \cdot 6 \\
155 \cdot 6 \\
154 \cdot 9 \\
165 \cdot 7 \\
172 \cdot 1 \\
175 \cdot 1 \\
166 \cdot 5 \\
195 \cdot 5\end{array}$ & $\begin{array}{r}3 \\
11 \\
43 \\
48 \\
54 \\
67 \\
47 \\
43 \\
26 \\
8 \\
14 \\
2 \\
3\end{array}$ & $\begin{array}{rr}+ & 5.8 \\
+ & 0.6 \\
+ & 5.7 \\
- & 13.1 \\
- & 4.1 \\
+ & 11.7 \\
+ & 4.7 \\
+ & 4.7 \\
+ & 4.7 \\
- & 1.1 \\
+ & 5.4 \\
+ & 24.0 \\
+ & 0.5\end{array}$ \\
\hline
\end{tabular}


weight $(a-b)$ The probability of such a corrected difference
arising by chance is 0.05 for the $21-26$ age group and rather less than 0.05 for the 40-45 age group.

To take account of the effect differences in height have on comparisons between mean weights of groups of individuals, attempts have been made to establish a suitable ponderal index relating these two physical characteristics. Controversy exists on the best way of calculating such an index (Khosla and Lowe, 1967). In the present study, ratios of

$$
\frac{\text { Mean weight }}{\text { Mean height }} \text { and } \frac{\text { Mean weight }}{\text { Mean (height squared) }}
$$

were calculated for the younger age groups (Table 3). The ratios of mean weight and mean height were employed rather than the mean of individual weight/ height ratios as this was considered more appropriate to the demonstration of group differences in the weight and height relationship. The calculation was made only for the younger age group as most interest occupation is minimal.

The difference in the ratio $\frac{\text { Mean weight }}{\text { Mean height }}$ between young motor mail drivers and postmen is statistically significant $(P=0.003)$, but the ratio

Mean weight Mean (height squared) is less significantly different $(P=0.055)$. These ratios are in agreement with the findings of the regression analysis in suggesting that most of the additional weight of the motor mail drivers is not due to their additional height.

It seems reasonable to assume, from the evidence in Tables 2 and 3, that the motor mail drivers were drawn from a physical group on average heavier for their height and probably taller than the group from which the postmen were drawn.

$\begin{array}{cc}\begin{array}{c}21-26 \\ \text { Age group } \\ \text { (lb.) }\end{array} & \begin{array}{c}40-45 \\ \text { Age group } \\ \text { (lb.) }\end{array} \\ 5.33 & 7.07 \\ \begin{array}{c}3.79 \times 0.46 \\ =1.74\end{array} & \begin{array}{c}4.26 \times 0.37 \\ =1.58\end{array} \\ 3.59 & 5.49\end{array}$
centres here where the influence of previous

\section{Discussion}

The above results suggest that physical differences existed between those men recruited for postal driving and postal delivery work. This was apparent in both the young and middle aged groups. Taller, heavier, and perhaps slightly broader men were recruited for driving duties. The evidence also suggests that the increased weight of drivers was not simply a reflection of their increased height, but was the result of some other physical characteristics, probably increased obesity.

That these physical characteristics were present in the younger age group indicates that they may have a constitutional origin, since there will have been little time for earlier occupation to have exerted any influence. Indeed, height is almost entirely an inherited characteristic which is not normally altered significantly by environmental factors.

These findings are in accord with my earlier studies of young busmen recruits, which indicate that taller, heavier, broader, more obese men prefer to drive rather than conduct buses.

The reason why these physical differences exist between those recruited for driving and non-driving duties is uncertain. Although the increased height of bus drivers was probably a reflection of management selection, there was strong evidence that their increased weight and obesity could not be explained in this way (Oliver, 1967). In the postal workers in the present study there is little to suggest that selection by the employer of a man for motor mail driving or postal delivery work is influenced by the candidate's physique. The specified minimum height for both groups was $5 \mathrm{ft} .4 \mathrm{in}$. $(162 \cdot 6 \mathrm{~cm}$.) so as to enable the employee to reach the letter sorting frames. There was no difference in the intellectual requirements for the two jobs. The only significant difference in requirements was that candidates for motor mail driving must have held a full driving licence and normally also have had commercial goods vehicle driving experience. Drivers have to pass a driving aptitude test and have a good knowledge of London.

Thus, previous occupation could have had an

TABLE 3

Weight and Height Ratios of Motor Mail Drivers and Postmen aged 21-26 Years

\begin{tabular}{|c|c|c|c|c|c|c|c|}
\hline \multicolumn{4}{|c|}{ Ratio } & \multirow{2}{*}{$\begin{array}{c}\begin{array}{c}\text { Motor mail } \\
\text { drivers }(M M D)\end{array} \\
2 \cdot 2180\end{array}$} & \multirow{2}{*}{$\frac{\begin{array}{c}\text { Postmen } \\
(P M N)\end{array}}{2 \cdot 1547}$} & \multirow{2}{*}{$\begin{array}{c}\begin{array}{c}\text { Difference } \\
(M M D-P M N)\end{array} \\
0.0633\end{array}$} & \multirow{2}{*}{$\begin{array}{c}\underset{\text { Probability }}{1} \\
0.003\end{array}$} \\
\hline$\frac{\text { Mean weight }}{\text { Mean height }}$ & $\cdots$ & $\cdots$ & $\cdots$ & & & & \\
\hline$\frac{\text { Mean weight }}{\text { Mean (height }}$ & uared) & . & . & 0.0324 & 0.0318 & 0.0006 & 0.055 \\
\hline
\end{tabular}

1 Probability based on the ' $t$ ' test of the differences in ratio of the means. 
effect on some of the physical characteristics of recruits to the grade of motor mail driver, but it is surprising if this could have become so apparent at such an early age. The more likely explanation, which is supported by the earlier studies of busmen, is that men who take up driving occupations are constitutionally different from those who prefer more active, but otherwise comparable, non-driving jobs. This is an important consideration in any investigation into the cause of disease (for example, ischaemic heart disease) to which men in driving or sedentary occupations may be susceptible.

I should like to acknowledge the assistance given to me in the preparation of this paper by Mr. J. J. Wheatley of the Statistics and Business Research Department of the General Post Office.

\section{References}

Heady, J. A., Morris, J. N., Kagan, A., and Raffle, P. A. B. (1961). Coronary heart disease in London busmen - A progress report with particular reference to physique. Brit. J. prev. soc. Med., 15, 143-153.

Khosla, T., and Lowe, C. R. (1967). Indices of obesity derived from body weight and height. Ibid., 21, 122-128.

Morris, J. N. (1959). Occupation and coronary heart disease. Arch. intern. Med., 104, 903-907.

-, Heady, J. A., and Raffle, P. A. B. (1956). Physique of London busmen - Epidemiology of uniforms. Lancet, 2, 569-570.

, - - Roberts, C. G., and Parks, J. W. (1953). Coronary heart disease and physical activity of work. Ibid., 2, 1053-1057, $111-1120$.

, and Raffle, P. A. B. (1954). Coronary heart-disease in transport workers. Brit. J. industr. Med., 11, 260-264.

Oliver, R. M. (1964). A clinical and biochemical study of trainee London busmen in relation to the ischaemic heart disease experience of drivers and conductors. M.D. Thesis, University of London.

- (1967). Physique and serum lipids of young London busmen in relation to ischaemic heart disease. Brit. J. industr. Med., 24, 181-188.

Received for publication December 6, 1968. 